\title{
Variations of thermospheric composition according to AE-C data and CTIP modelling
}

\author{
H. Rishbeth ${ }^{1}$, R. A. Heelis ${ }^{2}$, and I. C. F. Müller-Wodarg ${ }^{3,4}$ \\ ${ }^{1}$ School of Physics and Astronomy, University of Southampton, Southampton SO17 1BJ, UK \\ ${ }^{2}$ William B. Hanson Center for Space Sciences, The University of Texas at Dallas, P. O. Box 830688, Richardson, Texas \\ 75083-0588, USA \\ ${ }^{3}$ Atmospheric Physics Laboratory, University College London, 67-73 Riding House Street, London W1W 7EJ, UK \\ ${ }^{4}$ now at: Space and Atmospheric Lab, Imperial College London, Prince Consort Road, London SW7 2BW, UK
}

Received: 12 February 2003 - Revised: 16 June 2003 - Accepted: 18 June 2003 - Published: 1 January 2004

\begin{abstract}
Data from the Atmospheric Explorer C satellite, taken at middle and low latitudes in 1975-1978, are used to study latitudinal and month-by-month variations of thermospheric composition. The parameter used is the "compositional $P$-parameter", related to the neutral atomic oxygen/molecular nitrogen concentration ratio. The midlatitude data show strong winter maxima of the atomic/molecular ratio, which account for the "seasonal anomaly" of the ionospheric F2-layer. When the AE-C data are compared with the empirical MSIS model and the computational CTIP ionosphere-thermosphere model, broadly similar features are found, but the AE-C data give a more molecular thermosphere than do the models, especially CTIP. In particular, CTIP badly overestimates the winter/summer change of composition, more so in the south than in the north. The semiannual variations at the equator and in southern latitudes, shown by CTIP and MSIS, appear more weakly in the AE-C data. Magnetic activity produces a more molecular thermosphere at high latitudes, and at mid-latitudes in summer.
\end{abstract}

Key words. Atmospheric composition and structure (thermosphere - composition and chemistry)

\section{Introduction}

The seasonal anomaly in the ionospheric F2-layer was reported by Berkner et al. (1936) and has been extensively studied, for example, by Yonezawa (1971) and Torr and Torr (1973). Its main feature is that the peak electron density $N m \mathrm{~F} 2$ is greater in winter than in summer, most noticeably in high mid-latitudes in the North American/European and Australasian sectors at solar maximum. However, in other longitudes, and more generally in lower latitudes, the predominant variation of $N m \mathrm{~F} 2$ is more or less semiannual, with maxima at or soon after the equinoxes. This paper is mainly concerned with the seasonal changes in neutral composition

Correspondence to: I. C. F. Müller-Wodarg

(i.mueller-wodarg@imperial.ac.uk) of the thermosphere that largely determine this behaviour of $N m \mathrm{~F} 2$.

According to the generally accepted theory, $N m \mathrm{~F} 2$ depends on the atomic/molecular ratio (in particular, the $\mathrm{O} / \mathrm{N}_{2}$ ratio) of the ambient neutral air, and, of course, on the flux of solar ionizing radiation. Rishbeth and Setty (1961) suggested that the seasonal anomaly is caused by changes in the atomic/molecular ratio in the neutral thermosphere at F2-layer heights. Duncan (1969) suggested that these composition changes are caused by a global summer-towinter circulation in the thermosphere, with the atomic oxygen/molecular nitrogen $\left(\mathrm{O} / \mathrm{N}_{2}\right)$ ratio being decreased by upwelling of air in the tropics and summer mid-latitudes, and greatly enhanced in zones of downwelling that lie just equatorward of the winter auroral ovals. The location of the auroral zones, of course, depends on geomagnetic coordinates and, as a (rather complicated) consequence, the $\left(\mathrm{O} / \mathrm{N}_{2}\right)$ ratio and $N m \mathrm{~F} 2$ vary annually in some longitude sectors, semiannually in others. This was demonstrated in theoretical modelling by Millward et al. (1996a) and more comprehensively by Zou et al. (2000). The patterns of downwelling and upwelling were modelled by Rishbeth and Müller-Wodarg (1999). On the experimental side, the seasonal changes in the $\mathrm{O} / \mathrm{N}_{2}$ ratio at mid-latitudes were detected experimentally by von Zahn et al. (1973), using the ESRO 4 Gas Analyzer, and by Mauersberger et al. (1976), using the Open-Source Spectrometer on the Atmospheric Explorer AE-C satellite launched in November 1973 (Dalgarno et al., 1973). In this paper, we use data from the AE-C Neutral Atmosphere Temperature Experiment (NATE) (Spencer et al., 1973) to investigate how the $\mathrm{O} / \mathrm{N}_{2}$ ratio varies with season, latitude and longitude. In particular, we look for Duncan's zones of enhanced $\mathrm{O} / \mathrm{N}_{2}$ ratio near the winter auroral ovals. The AE-C data present a good opportunity to search for these zones, though, with its orbital inclination of $67^{\circ}$, the satellite does not reach the equatorward edge of the auroral ovals in all longitudes.

In Sect. 2 we describe in outline the instruments, the satellite orbit, and how we treated the data. We also briefly recall 
Point Distribution, Northern Summer, $\mathrm{Kp} \leq 3$

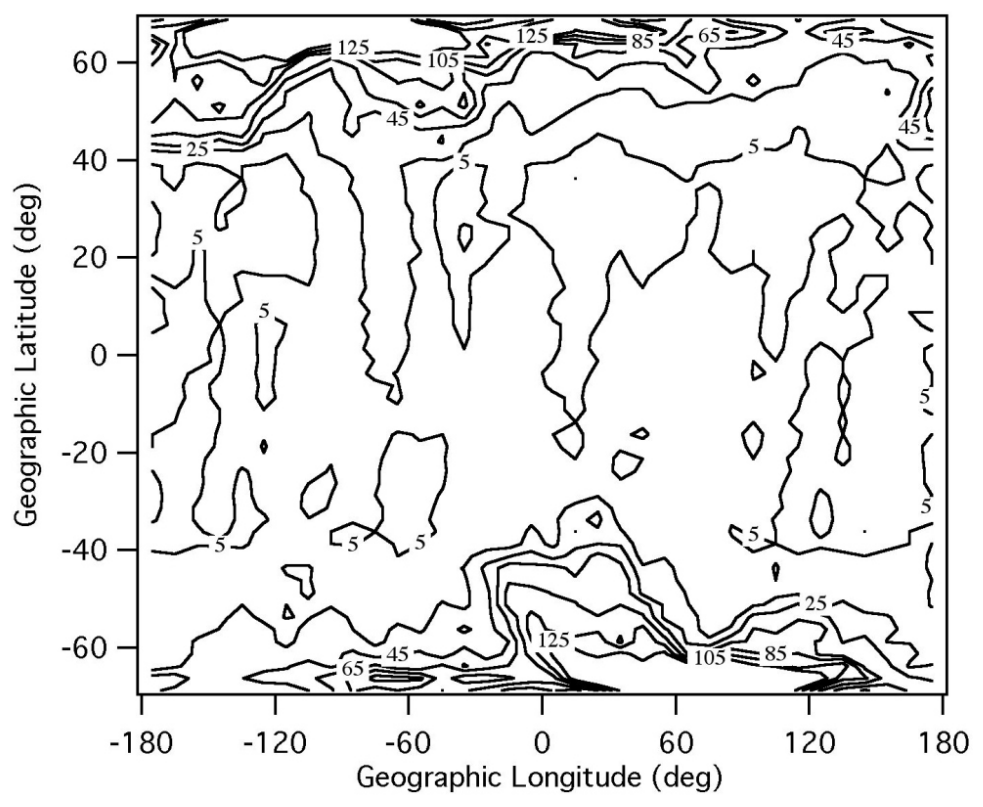

Fig. 1. Contour map showing number of data samples in AE-C composition data for northern summer, $K_{p} \leq 3$. the main features of the Coupled Thermosphere-IonospherePlasmasphere (CTIP) model (Fuller-Rowell et al., 1996, Millward et al., 1996b) as used by Rishbeth and MüllerWodarg (1999) and Zou et al. (2000), and in the present paper for comparison with the AE-C data. We then present and discuss the composition data and model outputs in two basic formats: plots versus latitude and longitude, for quiet and storm conditions (Sect. 3), and plots versus month and longitude (Sect. 4); in both sections we first present the data, and then the CTIP results, and in Sect. 5 we compare these with values from the well-known MSIS-86 empirical model (Hedin, 1987). Section 6 discusses the results in more detail and Sect. 7 summarizes the main findings. Appendix A explains the "compositional $P$-parameter" that we use to present both the data and the model results.

\section{Data, parameters and models}

\subsection{The NATE instrument on AE-C}

The AE-C satellite was launched in November 1973 into an elliptical orbit with an inclination of $67.3^{\circ}$ with an apogee of $4000 \mathrm{~km}$ and a perigee between $160 \mathrm{~km}$ and $130 \mathrm{~km}$. In April 1975 the orbit was circularized near $310 \mathrm{~km}$ and maintained near this altitude until March 1977, when a circular orbit near $390 \mathrm{~km}$ was established. The orbit finally decayed in November 1978.

We use data from the Neutral Atmosphere Temperature Experiment, NATE (Spencer et al., 1973) operating at altitudes between $200 \mathrm{~km}$ and $450 \mathrm{~km}$. Thus, the data are predominantly collected from the circular orbit phases during 1975-1978. During this period, the monthly mean solar
$10.7 \mathrm{~cm}$ flux was quite low, in the range of 70-100 units, and we have not divided the data according to solar flux. The NATE instrument was chosen to provide the largest continuous data set during that period. The spectrometer has a closed source in which the collected gases are in equilibrium with the chamber walls. The atomic oxygen is, therefore, detected as molecular oxygen, and the atomic oxygen concentration is derived by accounting for the factor of 2 in producing molecular oxygen and the ram pressure increase in the chamber produced by the supersonic motion of the spacecraft through the gas. The ambient molecular oxygen concentration can contribute up to $5 \%$ of the signal at the lowest altitudes considered, so the atomic oxygen concentration may be slightly overestimated. The neutral composition is derived directly from the spectrometer outputs, while the neutral temperature is derived by examining the change in pressure as a baffle is scanned across the entrance aperture. The associated fitting procedure yields temperature data with reliability that depends upon conditions and delivers a data set that is less extensive than the composition data.

\subsection{Treatment of the data}

The data are recovered from unified abstract files that contain values for each pass averaged over a 15-s time interval or about $110 \mathrm{~km}$ along the satellite path. The data are thus spaced about $1^{\circ}$ in latitude at low and middle latitudes and about $1^{\circ}$ in longitude at the highest latitudes, with each 15 s sample representing the average of about 4 points. In this work we examine the global behaviour of the neutral composition by collecting the data in cells of $2.5^{\circ}$ in latitude and $10^{\circ}$ in longitude. This bin size was chosen to provide a reasonable spatial resolution with a sensible sample size in most 
$\mathrm{O} / \mathrm{N} 2,+55$ to +68 Geog. $\mathrm{Kp} \leq 3$

Alt $~ 390 \mathrm{~km}$

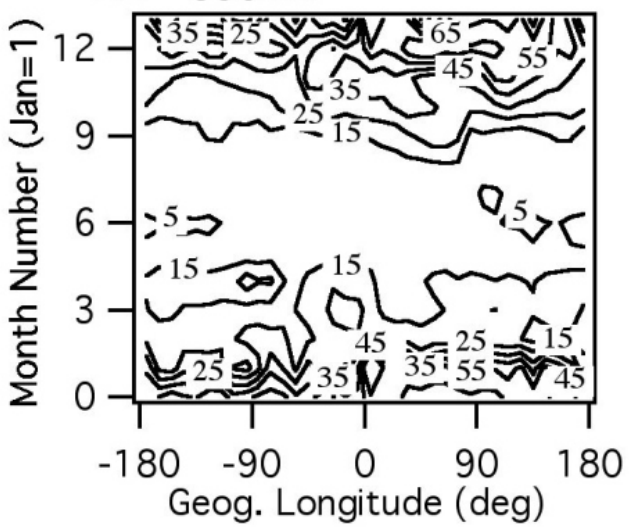

P-parm, +55 to +68 Geog. $\mathrm{Kp} \leq 3$ Alt $\sim 390 \mathrm{~km}$

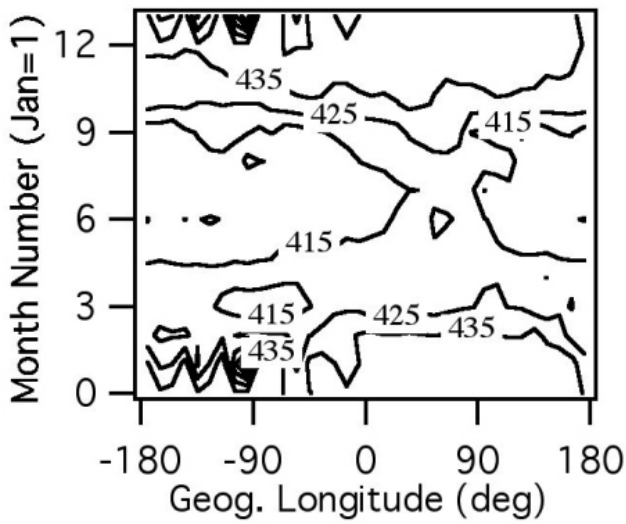

O/N2, +55 to +68 Geog. $\mathrm{Kp} \leq 3$

Alt $\sim 280-400 \mathrm{~km}$

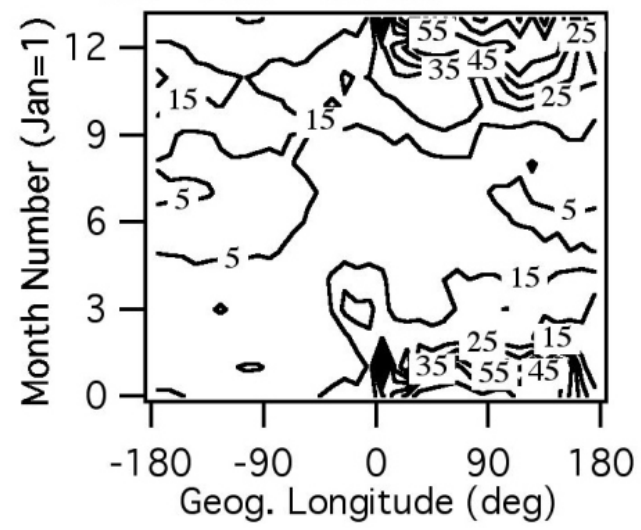

P-parm, +55 to +68 Geog. $\mathrm{Kp} \leq 3$

Alt $\sim 280-400 \mathrm{~km}$

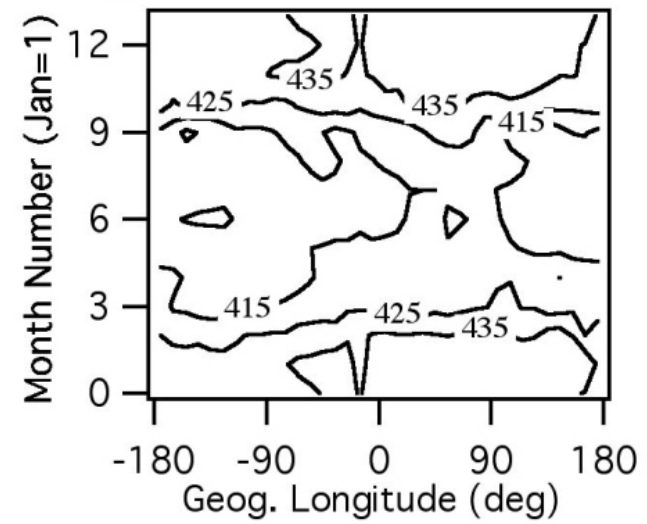

Fig. 2. Contour plots for geographic latitudes $55^{\circ} \mathrm{N}$ to $68^{\circ} \mathrm{N}$ for $K_{p} \leq 3$, versus longitude and month. Above: Neutral O/N 2 concentration ratio at heights $390 \mathrm{~km}$ (left), 280-400 km (right). Below: $P$-parameter at heights $390 \mathrm{~km}$ (left), 280-400 km (right).

bins. The AE-C satellite was not operated continuously, and the planned operations resulted in the majority of the data being taken at latitudes above $50^{\circ}$ in each hemisphere.

During this study we examine variations in composition as a function of latitude and longitude for a given season and as a function of longitude and season in a given latitude range. The number of data points is insufficient to examine global distributions separated by local time. However, by comparing the data obtained at 09:00-15:00 LT with that obtained for all local times, we found that the composition does not vary greatly from day to night (in line with theoretical results, see Sect. 5), so we have combined data from all local times. Although separating the data by $K_{p}$ produces some gaps in the global distributions, we are able to illustrate the first order effects of magnetic activity.

In studying latitude and longitude variations, we group the months November-February as northern winter, MayAugust as northern summer, and March-April/SeptemberOctober as equinox. Figure 1 shows the point distribution in latitude and longitude for the northern summer months during quiet times. This distribution is also representative of quiet conditions during the northern winter and equinox months. Note that above $50^{\circ}$ latitude there are at least 10 samples through each latitude and longitude cell, reducing to just $2-10$ points at lower latitudes. Approximately $10 \%$ of the cells at lower latitudes contain only one sample. When the data are collected in specific latitude regions for detailed study of seasonal variations, the point distribution is such that each month/longitude cell contains at least 10 points and usually more than 20 points.

The restricted operations schedule for the AE-C satellite leads to non-uniformity in longitude samples at low latitudes. Thus, empty cells with no data samples may reside adjacent to more frequently sampled locations, and in such cases large and unphysical longitude gradients may appear (as will be seen in the figures presented in Sect. 3).

\subsection{The $\mathrm{O} / \mathrm{N}_{2}$ ratio and the $P$-parameter}

The data used in this study are largely obtained at altitudes near $300 \mathrm{~km}$ and $400 \mathrm{~km}$. The upper contour plots in Fig. 2 show the neutral $\mathrm{O} / \mathrm{N}_{2}$ concentration ratio versus longitude 
and month at geographic latitude $55-68^{\circ} \mathrm{N}$. The left panel is for heights near $390 \mathrm{~km}$, the right panel combines data for heights between about 280 and $400 \mathrm{~km}$. Both show the largest values of the $\left(\mathrm{O} / \mathrm{N}_{2}\right)$ ratio in winter, particularly the left-hand panel which has a greater range of values. To improve the sample statistics we should include data taken over a range of altitude; but since the $\mathrm{O} / \mathrm{N}_{2}$ ratio increases rapidly upward, typically with an exponential scale height of $80 \mathrm{~km}$, the average values are compromised by changes in the satellite height and the details are different.

To overcome this problem, we use the composition $P$-parameter, as defined by Rishbeth and MüllerWodarg (1999), which enables us to combine data from all heights sampled by the satellite. This parameter is heightindependent if atomic oxygen and molecular nitrogen are distributed vertically with their own scale heights (Eqs. A3 and A4 in Appendix A), as should be the case above about $120 \mathrm{~km}$, except perhaps in strongly disturbed conditions. As explained there, we do not include the temperature term of the full $P$-parameter, as doing so reduces the size of the data set and increases the variability due to uncertainties in the derived neutral temperature. As a rough guide, a change in $P$ of +1 unit increases the $\mathrm{O} / \mathrm{N}_{2}$ ratio by about $5 \%$ or a factor of 1.05 ; a change of +10 units increases the $\mathrm{O} / \mathrm{N}_{2}$ ratio by about a factor of 1.8. The use of the $P$-parameter is beneficial at all locations, since it increases the sample size while retaining information about the $\mathrm{O} / \mathrm{N}_{2}$ ratio. At low latitudes the sample size is still quite small, leading to apparently more spatial structure.

In the lower part of Fig. 2, we see that the details of the left-hand and right-hand panels are very similar, except in the auroral regions in western longitudes. Here the high winter values of $P$ may be expected to be variable, and affected by differences in sampling between the left and right panels.

\subsection{The CTIP model}

The Coupled Thermosphere-Ionosphere-Plasmasphere (CTIP) model (Fuller-Rowell et al., 1996; Millward et al., 1996b) calculates globally the coupled thermosphereionosphere system by solving the equations of energy, momentum and continuity for neutral particles $\left(\mathrm{O}, \mathrm{O}_{2}, \mathrm{~N}_{2}\right)$ and ions $\left(\mathrm{O}^{+}, \mathrm{H}^{+}\right)$through explicit time integration. The model has its lower boundary at $80 \mathrm{~km}$ altitude and for ion calculations reaches out to $10000 \mathrm{~km}$ in regions of open magnetic field lines (at high latitudes) and $L=3.5$ in regions of closed magnetic field lines (at low to mid-latitudes). The dynamical, energetic and chemical neutral-ion coupling is calculated self-consistently. In addition to solar heating, the atmosphere calculated by CTIP is driven externally by a high latitude convection pattern, as parameterized by Foster et al. (1986) and a high latitude particle precipitation model by Fuller-Rowell and Evans (1987). It can be run for any season and level of solar and geomagnetic activity, and produces global values of neutral and ion winds, temperatures and composition. CTIP has been used in numerous studies examining the morphology of thermospheric and ionospheric composition and dynamics, such as those by Rishbeth and Müller-Wodarg (1999), Zou et al. (2000) and Rishbeth et al. (2000). For this study, the program is run to reach a stable condition for each month, which takes about 20 days of scale time and, therefore, does not accurately represent any seasonal phase lags.

\section{AE-C maps of $P$-parameter vs. latitude and longitude}

Figure $3 \mathrm{a}$ and $\mathrm{b}$ shows the distribution in latitude and longitude of the $P$-parameter derived from the AE-C data, for northern summer and for low and high magnetic activity ( $K_{p} \leq 3$, above; $K_{p} \geq 3$ below). The red curves show the positions of magnetic $L$-values $3.5,4,4.5$ which correspond to magnetic invariant latitudes of $58^{\circ}, 60^{\circ}, 62^{\circ}$. As previously mentioned, large spatial gradients may appear in the vicinity of cells with few or no data samples. In these and all subsequent plots, redder colours mean increased $P$ and a more atomic thermosphere; bluer colours mean decreased $P$ and a more molecular thermosphere.

A predominant summer-to-winter (north-to-south) increase of $P$, and, therefore, of the $\mathrm{O} / \mathrm{N}_{2}$ ratio at fixed pressure-levels, is seen at all longitudes. As discussed in Sect. 6, we attribute this to the global thermospheric circulation. The greatest values of $P$ occur just equatorward of the auroral zone in the winter (southern) hemisphere. This is most visible at longitudes between $40^{\circ}$ and $180^{\circ} \mathrm{E}$, where the southern auroral zone has its most equatorward excursion, but the magnetic control of the $P$-parameter maximum is evident at all longitudes.

The most obvious effect of magnetic activity is the bluer colour at high magnetic latitudes, $L>4$, in the north-west (summer) sector of Fig. $3 \mathrm{~b}$ and, to a lesser extent, in the south-east (winter) sector. The changes in $P$ are 5-10, greater in winter than in summer. This is consistent with the expected upwelling of the atmosphere in the auroral zone caused by Joule and particle heating. This heating also moderates the summer to winter flows, with the result that the maxima of $P$ are higher and are shifted equatorward of their quiet-time locations. At mid-latitudes, the magnetic disturbance has less effect, but there is evidence of reduced $P$ in summer and possibly slightly increased $P$ in winter.

Figure $4 \mathrm{a}$ and $\mathrm{b}$ shows $P$ at northern winter, at low and high magnetic activity. The same features described in Fig. 3 can be seen here, but the picture is less clear because of the slightly poorer sample statistics. Again, $P$ increases from summer to winter (south to north), but the peak value appears less well aligned with the magnetic $L$-values. During disturbed conditions, $P$ is reduced at high magnetic latitudes in the southeast (summer) sector, as before, and to some extent in northern (winter) high latitudes, too, but the displacements of the peak in $P$ cannot be resolved because of small sample numbers.

Figure 5a and $\mathrm{b}$ shows $P$ at low and high magnetic activity at spring and fall equinox. These two seasons are sufficiently similar to be combined, and are fairly symmetrical 
a) Northern Summer, $K p \leq 3$

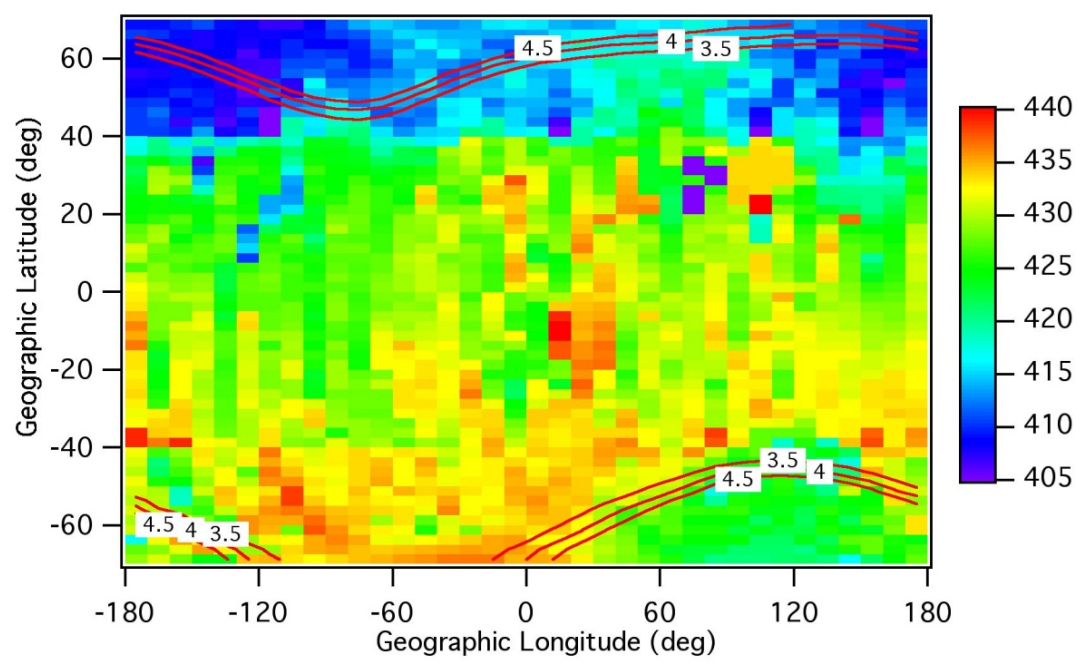

b) Northern Summer, $\mathrm{Kp} \geq 3$

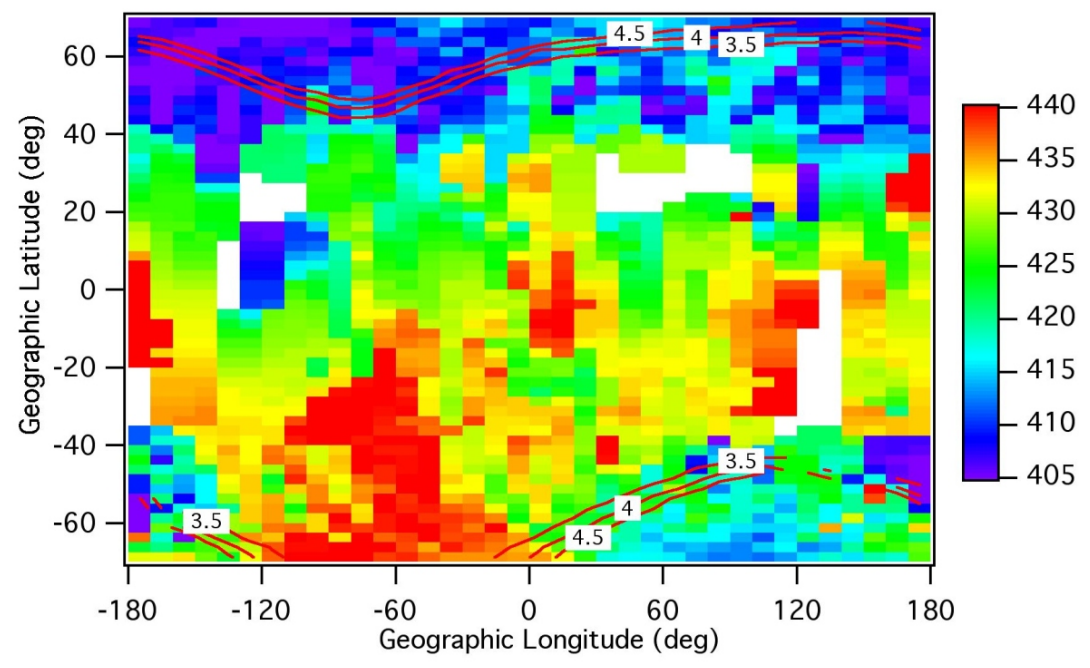

Fig. 3. AE-C: Maps of $P$-parameter for northern summer for (a) quiet magnetic conditions $\left(K_{p} \leq 3\right.$ above) and (b) disturbed magnetic conditions ( $K_{p} \geq 3$, below). Red curves show magnetic $L$-values.

with respect to the edge of the auroral zones, particularly in disturbed conditions. The effect of magnetic activity is to increase $P$ at low latitudes and decrease the minimum values in the auroral zones. The detailed variations with latitude and longitude are due partly to the geomagnetic field configuration, but they may also be influenced by seasonal variations that are not entirely removed by averaging over the four equinox months, in addition to the effects arising from the limited bin samples mentioned in Sect. 2.2. There remains a possibility of genuine regional differences in composition, on top of the above, but more study would be needed to establish their reality.

Figures 3 and 4 clearly illustrate that peaks in the $P$ parameter occur in the winter hemisphere at longitudes where the auroral oval is at its highest geographic latitude. This is most obvious in the south (Fig. 3a and b), where the magnetic dip pole is at lower geographic latitude than in the north $\left(67^{\circ} \mathrm{S}\right.$ as compared to $\left.78^{\circ} \mathrm{N}\right)$, but is also seen in northern winter (Fig. 4a). The minimum values of $P$ occur in the summer hemisphere, near the longitudes where the auroral zone is at its lowest latitude. We do not show maps in magnetic coordinates, because at higher southern latitudes there is a large data gap at longitudes $30-90^{\circ} \mathrm{W}$ where the satellite does not reach high $L$-values.

If we take $P$ as an indicator of thermospheric upwelling and downwelling, the plots suggest that upwelling exists at high magnetic latitudes, strongly in summer and weakly in winter, too, and is enhanced by magnetic activity (northwest corner of Fig. 3b, southeast corner of Fig. 4b). At both solstices, the winter zone of strongest downwelling (the greatest $P$-values and the most atomic thermosphere) is also magnetically aligned. It lies at $L$-values of 2.5-3 (magnetic latitudes 
a) Northern Winter, $\mathrm{Kp} \leq 3$

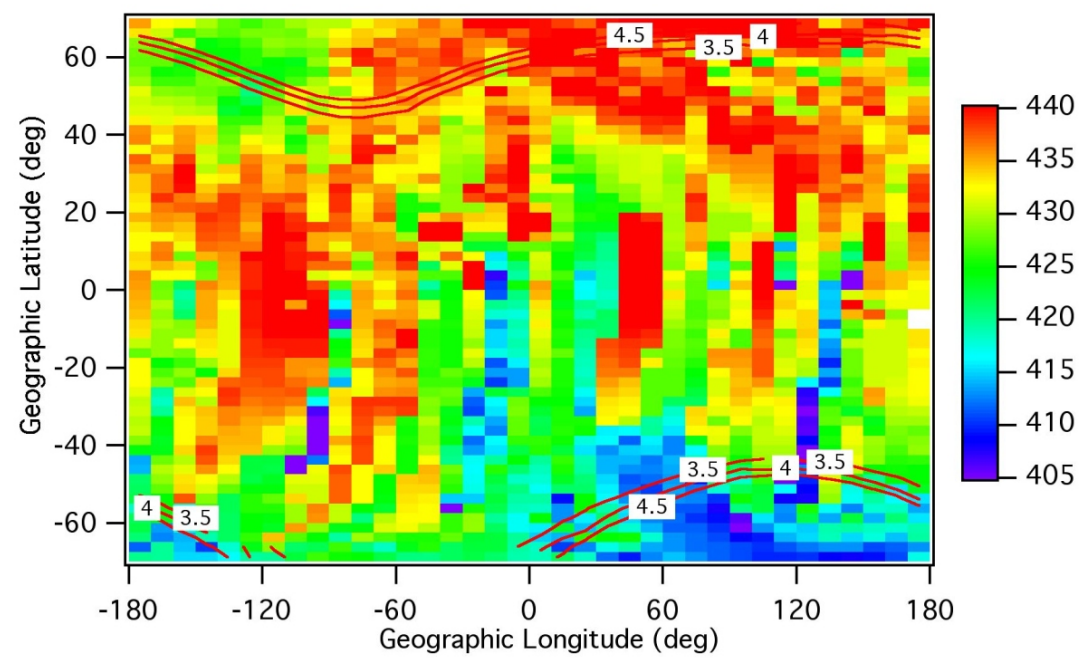

b) Northern Winter, $K p \geq 3$

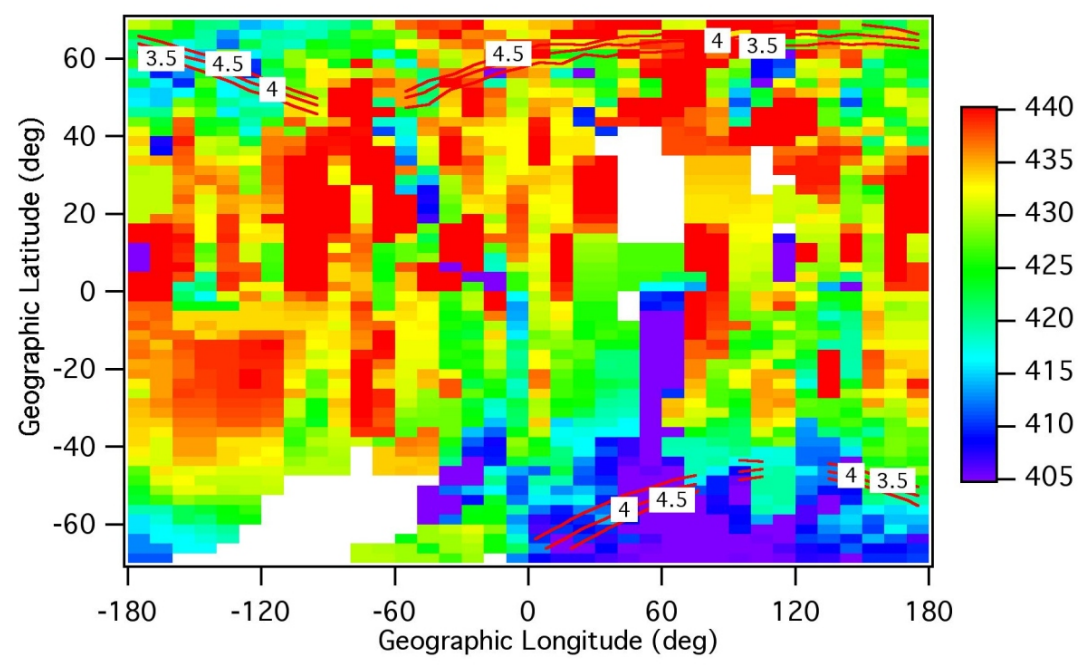

Fig. 4. AE-C: Maps of $P$-parameter for northern winter for (a) quiet magnetic conditions $\left(K_{p} \leq 3\right.$ above) and (b) disturbed magnetic conditions ( $K_{p} \geq 3$, below). Red curves show magnetic $L$-values.

$\left.51-55^{\circ}\right)$, equatorward of the auroral zones, as predicted by Duncan (1969).

\section{$4 \quad$ AE-C and CTIP maps of $P$-parameter vs. month and longitude}

Figure 6 displays the data and model results in plots of $P$ versus month and longitude at low magnetic activity, to show how the variations of composition vary throughout the year in five broad zones of latitude. There is some overlap, in that December is shown twice (months 0 and 12) and so is January (months 1 and 13). AE-C data are on the left, CTIP model results on the right. Not surprisingly, the CTIP results are fairly smooth, and lack much of the detail shown by the AE-C data.
The colour ranges are chosen to encompass the full seasonal variation seen in the satellite data and the model data. A slight difference between their scales facilitates a comparison over latitude within a data set, with a little compromise to the comparison of features seen in the satellite and model data. If we use the same colour scale for every panel, the five AE-C panels are noticeably bluer in colour (indicating lower $P$-values) than the five corresponding CTIP panels. To adjust the colour scales to obtain a better colour match between the two sets of panels, we first computed the mean value of $P$ for all ten panels, with the following results for the five latitude ranges (north to south, rounded to nearest integers):

- AE-C: 425, 426, 431, 427, 423; mean 427;

- CTIP: 450, 443, 438, 441, 443; mean 443. 
a) Spring/Fall Equinox, $\mathrm{Kp} \leq 3$

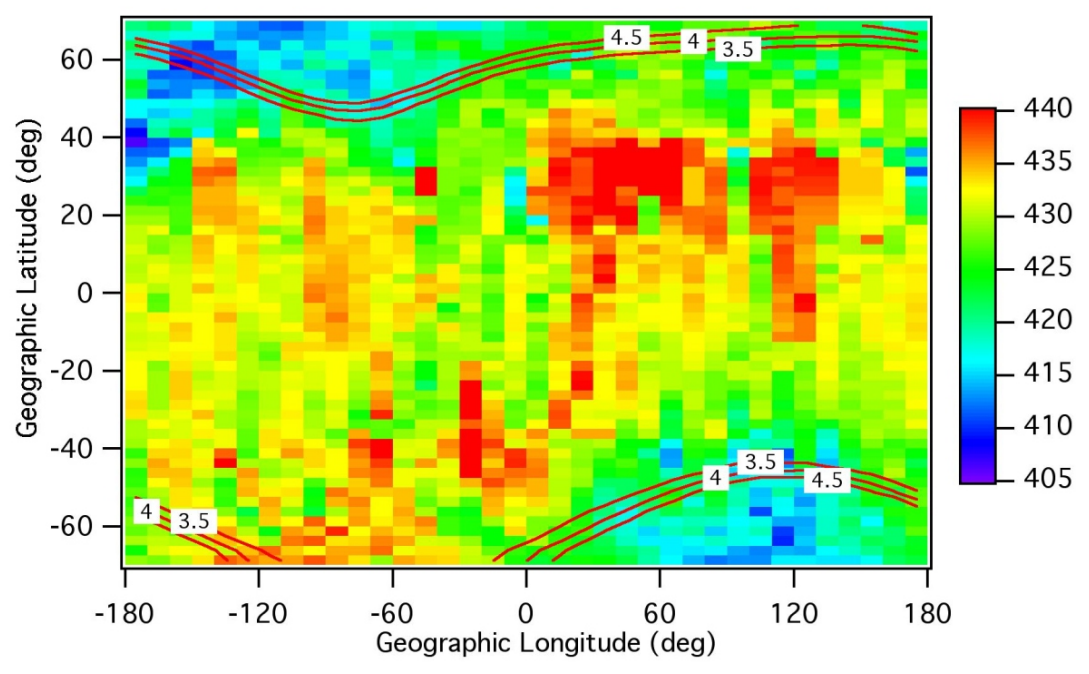

b) Spring/Fall Equinox, $\mathrm{Kp} \geq 3$

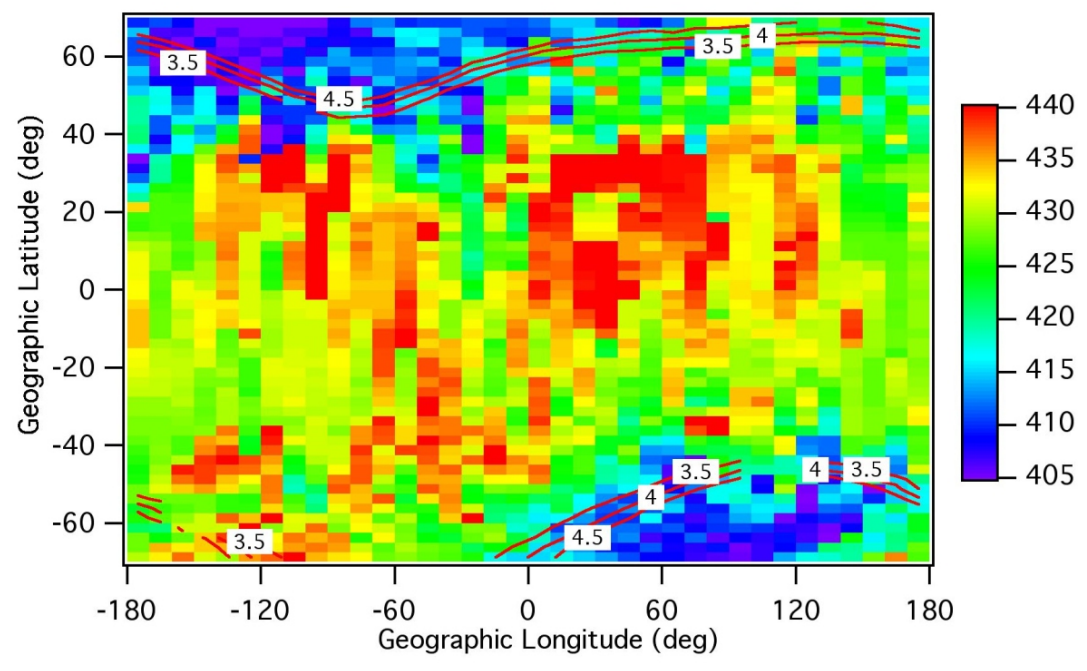

Fig. 5. AE-C: Maps of $P$-parameter for equinox (March, April, September, October) for (a) quiet magnetic conditions $\left(K_{p} \leq 3\right.$, above) and (b) disturbed magnetic conditions ( $K_{p} \geq 3$, below). Red curves show magnetic $L$-values.

The difference between the overall mean AE-C and mean CTIP values is $443-427=16$, which is the adjustment we made in the colour scales. The mean values of $P$ for the data and the model now match quite well in colour, but the range of $P$ is smaller in the data than in the model, and the highest $P$-values in the AE-C panels only reach orange colours, as compared to the reds in the CTIP panels.

\subsection{Mid-latitudes}

At $50-70^{\circ} \mathrm{N}$ (top row), where summer months are in the centre of the panels and winter months are at the top and bottom, the summer/winter variation stands out strongly. Both summer and winter values of $P$ are greater in eastern longitudes than in western. The lowest summer values of $P$ are found at Pacific longitudes $130-180^{\circ} \mathrm{W}$ in the data, but further east in the model at Atlantic/American longitudes $0-100^{\circ} \mathrm{W}$. CTIP clearly overestimates the winter values of $P$; this indicates that the winter downwelling, which increases $P$, is less pronounced in the AE-C data than in CTIP. At $30-50^{\circ} \mathrm{N}$ the seasonal variations are smaller, both in data and model, but are in the same sense as at $50-70^{\circ} \mathrm{N}$. Again, the summer minimum is over the Pacific in the data, but over the Atlantic in the model.

Turning to southerly mid-latitudes (two bottom rows of Fig. 6), summer months are at the top and bottom of the panels and winter months in the centre. At $30-50^{\circ} \mathrm{S}$ the summer minima in the AE-C values are now in east longitudes in the African/Indian Ocean sector, $30-80^{\circ} \mathrm{E}$. In west longitudes, greatest $P$ tends to occur around or after equinox (April and October), giving a semiannual pattern superimposed on the winter/summer variation. The semiannual tendency also ap- 

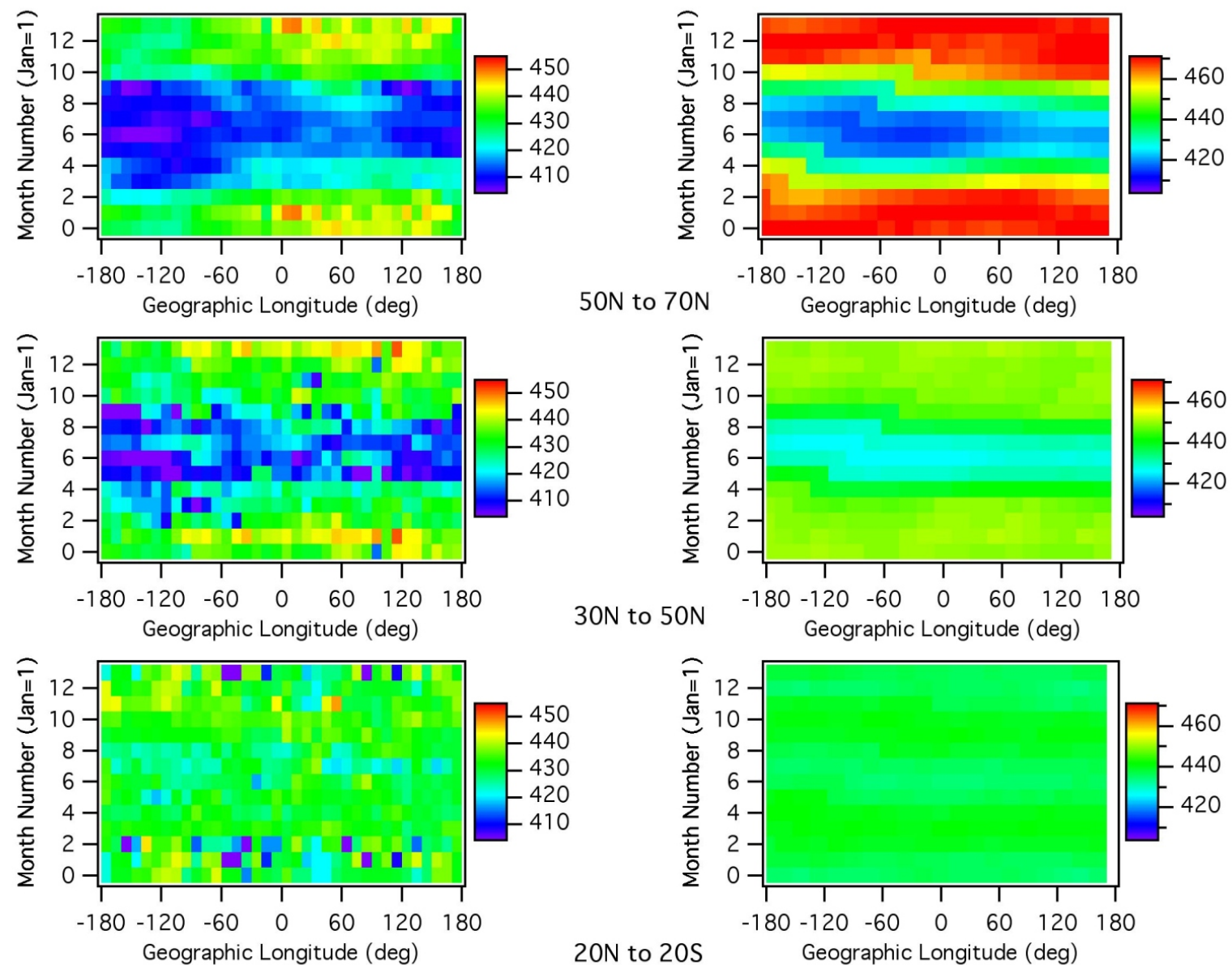

$30 \mathrm{~N}$ to $50 \mathrm{~N}$
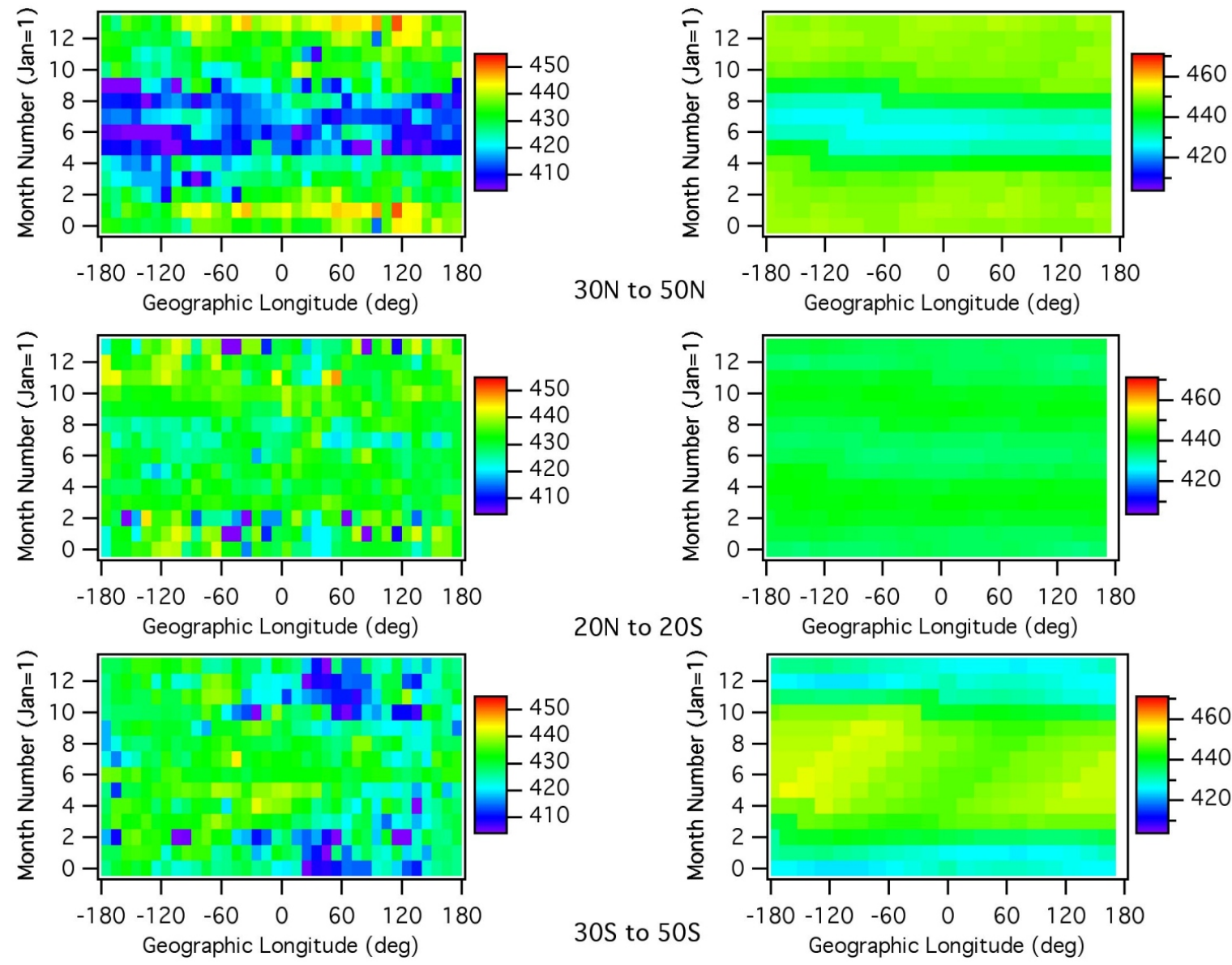

$20 \mathrm{~N}$ to $20 \mathrm{~S}$
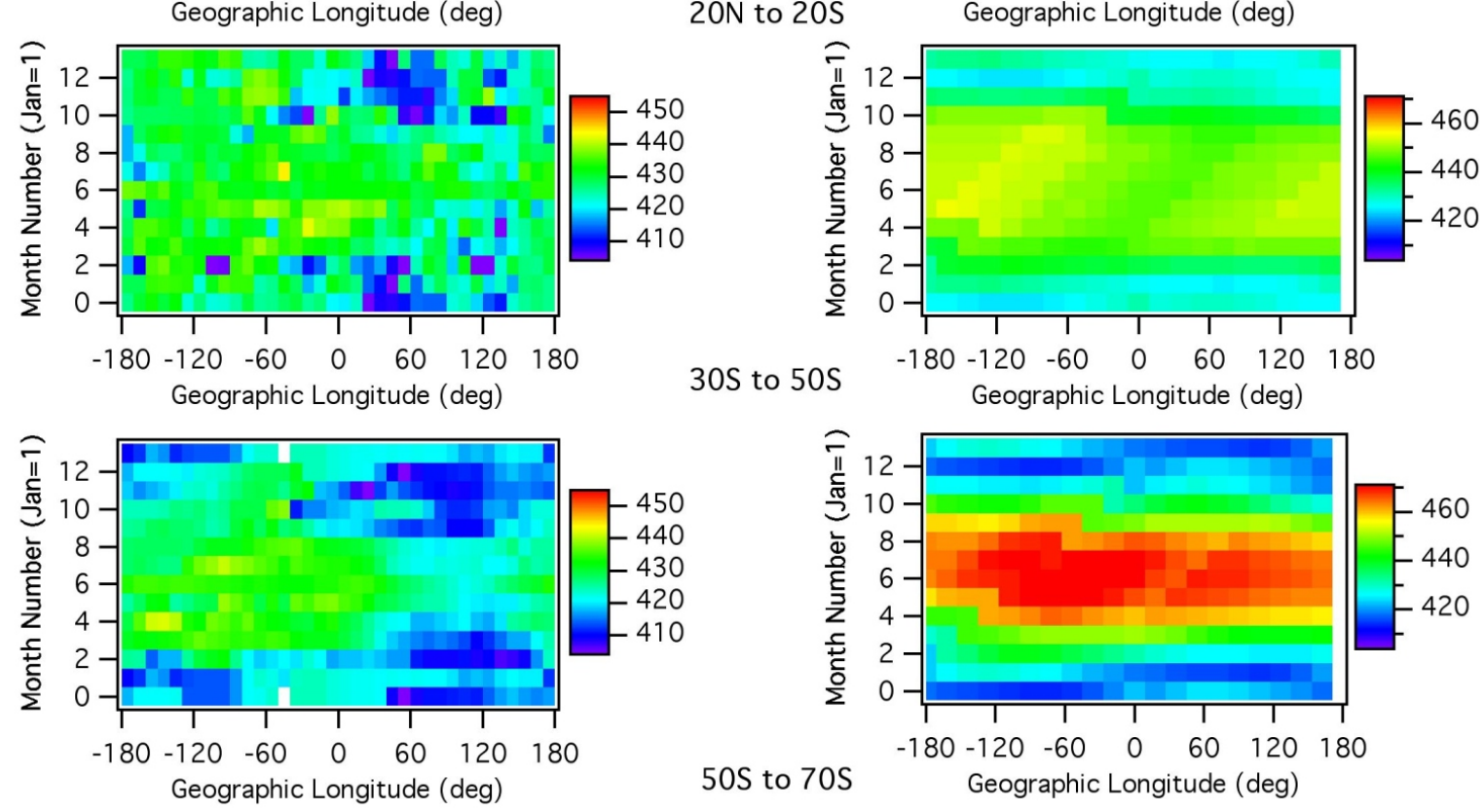

$30 \mathrm{~S}$ to $50 \mathrm{~S}$

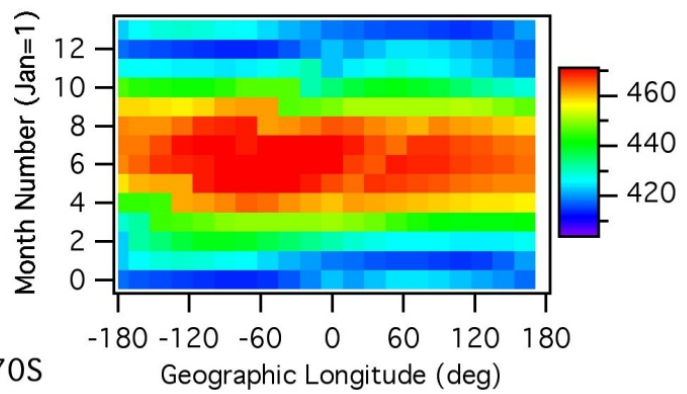

Fig. 6. $P$-parameter from AE-C data (left) and CTIP (right) vs. month and longitude for $K_{p} \leq 3$, for five ranges of geographic latitude. Top to bottom: $50-70^{\circ} \mathrm{N}, 30-50^{\circ} \mathrm{N}, 20^{\circ} \mathrm{S}$ to $20^{\circ} \mathrm{N}, 30-50^{\circ} \mathrm{S}, 50-70^{\circ} \mathrm{S}$ 
Table 1. $P$-parameters at midday from models and data.

\begin{tabular}{llllllll}
\hline Station & Dec & Mar & June & Sept & Mean & Dec-June & Equx-Solstice \\
\hline Slough: & & & & & & & \\
MSIS & 442 & 434 & 418 & 434 & 432 & 24 & 4 \\
AE-C & 435 & 420 & 416 & 423 & 424 & 19 & -4 \\
CTIP & 452 & 450 & 422 & 448 & 443 & 30 & 12 \\
\hline Port Stanley: & & & & & & & \\
MSIS & 424 & 438 & 437 & 438 & 434 & -13 & 8 \\
AE-C & 430 & 437 & 431 & 431 & 432 & -1 & 3 \\
CTIP & 423 & 446 & 451 & 447 & 442 & -29 & 9 \\
\hline Equator: & & & & & & & \\
MSIS & 432 & 437 & 429 & 437 & 434 & 3 & 6 \\
AE-C & 425 & 427 & 432 & 434 & 429 & -5 & 2 \\
CTIP & 432 & 438 & 432 & 437 & 435 & 0 & 5 \\
\hline
\end{tabular}

pears weakly in western longitudes in the AE-C panel for $50-70^{\circ} \mathrm{S}$, but rather as a broad plateau extending from autumn (months 3-4) to spring (months 9-10). In the southern CTIP panels, any semiannual tendency is hidden by the unrealistically high mid-winter maxima of $P$.

Though not shown here, the distributions of $P$ plotted in magnetic $L$-coordinates are quite similar at mid-latitudes to those in geographic coordinates but, as previously remarked, they lack complete longitude coverage at high latitudes in the south.

\subsection{The equatorial zone}

The centre row of Fig. 6 shows the equatorial zone, between $20^{\circ} \mathrm{S}$ and $20^{\circ} \mathrm{N}$ geographic. The range of $P$-values throughout the year is smaller than at mid-latitudes, particularly in the CTIP panel where the range is $<10$. The semiannual variation in the CTIP results (right), of about 5 units, appears very weakly in the AE-C data (left). In western longitudes the AE-C plot shows an annual variation of about 5 units in $P$, with maximum in November-February and minimum in June-August. The hemispheric differences may be connected with differences in the magnetic latitude, since in the American sector the magnetic equator is south of the geographic equator and the data in Fig. 6 come mostly from north magnetic latitudes. Conversely, in the Asian equatorial sector the data come mostly from south magnetic latitudes.

A plot of the AE-C $P$-values for the magnetic equatorial zone (Rishbeth, 2003), covering magnetic latitudes $20^{\circ}-$ $20^{\circ} \mathrm{N}$, also shows a strong annual (December-June) variation of $P$ in most longitudes, which tends to conceal any semiannual pattern. However, at $60^{\circ}-90^{\circ} \mathrm{E}$ the pattern is weakly semiannual. The greater strength of the annual pattern in the "magnetic" plot may be attributed, at least partly, to summer/winter differences of composition, bearing in mind that the "magnetic equatorial zone" extends into geographic midlatitudes in some longitude sectors.
As discussed by Rishbeth et al. (2000), the equinox maxima of $P$ indicate that the thermosphere is less disturbed at equinox than it is at solstice, when solar input is continuous at high summer latitudes and drives the strong summer-towinter circulation (Fuller-Rowell, 1998).

\section{Comparisons of AE-C, CTIP and MSIS values of $P$-parameter}

We used the MSIS-86 model (Hedin, 1987) to compute the $P$-parameter from Eq. (A4) for Slough $\left(52^{\circ} \mathrm{N}, 1^{\circ} \mathrm{W}\right)$ and Port Stanley $\left(52^{\circ} \mathrm{S}, 58^{\circ} \mathrm{W}\right)$, for solar $10.7 \mathrm{~cm}$ flux of 100 units and low magnetic activity $\left(A_{p}=4\right)$. We found that, as expected, $P$ is almost height-independent above $200 \mathrm{~km}$, while from $200 \mathrm{~km}$ down to $120 \mathrm{~km}$ it increases by about 7 units. In contrast, using the more complete formula (A3), $P$ is virtually height-independent down to $150 \mathrm{~km}$, and decreases by only about 5 units from 150 to $120 \mathrm{~km}$. At $300 \mathrm{~km}$ height, we found that MSIS $P$ is smaller at midnight than at noon, but only by about 4 units, which supports our decision (Sect. 2.2) to use all local times in analysing the AE-C data. We also used MSIS to compute $P$ for an "equator" point near $\left(0^{\circ}, 40^{\circ} \mathrm{W}\right)$, which is approximately where the geographic and magnetic equators cross (the MSIS values at $0^{\circ}, 160^{\circ} \mathrm{W}$, the other longitude where the equators cross, are just 1 unit lower than at $40^{\circ} \mathrm{W}$ ). Table 1 shows the noon values of $P$ at these places from the MSIS and CTIP models and the AE-C data for December and June solstices and March and September equinoxes. In the case of AE-C, the data are averages over an area within $5^{\circ}$ of the required point, to remove some of the point-to-point variations. Consider the means of the four seasonal values of $P$, shown in the column headed "Mean". At Slough and Port Stanley, these CTIP means are markedly higher than the others, except in local summer, which implies that the CTIP thermosphere is too atomic (recall that each unit of $P$ corresponds to about $5 \%$ in the $\mathrm{O} / \mathrm{N}_{2}$ ratio). This is mainly because CTIP gives too big a 
winter/summer variation, especially at Port Stanley. At Port Stanley and at the equator, the semiannual (equinox/solstice) variation in the AE-C data is much smaller than that given by MSIS and CTIP; at Slough the equinox/solstice difference in the AE-C and MSIS values of $P$ is small and not significant, with the larger difference in CTIP being due to the small summer value of $P$. In most cases the March and September values of $P$ are equal or nearly so, with the exceptions of the AE-C data for Port Stanley (greater in March) and at the equator (greater in September). Since the AE-C data were used in constructing the MSIS model, we might expect the MSIS and AE-C values of $P$ to agree, but we have no explanation as to why they do not, beyond the slight overestimate of the atomic oxygen concentration mentioned in Sect. 2.1.

At the equator, MSIS and CTIP agree well, with a marked semiannual variation not seen in the AE-C values, which peak in September. The annual variation is not prominent in the AE-C data at longitudes around $35^{\circ} \mathrm{W}$, and the (December-June) difference may not be typical of low latitudes generally; in any case the data in this vicinity have rather poor statistics.

\section{Discussion}

The most obvious result is that, in both hemispheres but especially the north, the $\mathrm{O} / \mathrm{N}_{2}$ ratio and the derived $P$ parameter are greater in winter than in summer at all longitudes, denoting substantial seasonal changes in the neutral atomic/molecular composition. We find that the MSIS atmosphere is more atomic than the AE-C data indicate, typically by about 5 units of $P$, corresponding to a difference of about $30 \%$ in the $\mathrm{O} / \mathrm{N}_{2}$ ratio. On the other hand, the CTIP computations give a substantially more molecular atmosphere than the AE-C data indicate; at northern mid-latitudes (Slough) the seasonally averaged difference amounts to about 20 units of $P$, which corresponds to a difference of about $3: 1$ in the $\mathrm{O} / \mathrm{N}_{2}$ ratio. We do not pursue the reasons for these differences.

With the level of smoothing we used, the coverage of latitude and season is reasonably complete. The general patterns of the $\mathrm{O} / \mathrm{N}_{2}$ ratio and the $P$-parameter are similar (Fig. 2), but the $P$-parameter is much more useful, because it enables data from a great range of height to be combined. Omitting the temperature term in the $P$-parameter (Eq. A4) avoids difficulties with incomplete temperature data, without seriously affecting the most valuable property of $P$, namely its independence of height.

The "winter downwelling" and its effects on the $\mathrm{O} / \mathrm{N}_{2}$ ratio and $N m \mathrm{~F} 2$ are well displayed by CTIP modelling. According to Duncan (1969), the downwelling zones are just equatorward of the auroral ovals. Consequently, the situation in longitude sectors adjacent to the (geographic) longitudes of the magnetic poles (which we call "near-pole" longitudes) differs from that in sectors remote from the (geographic) longitudes of the magnetic poles (which we call "far-from-pole" longitudes) (Rishbeth and Müller-Wodarg, 1999; Rishbeth et al., 2000). In "near-pole" longitudes, the downwelling zones are at relatively low geographic latitudes (around $50^{\circ}$ ), which are sunlit at noon in mid-winter (though at large solar zenith angles), and winter $N m \mathrm{~F} 2$ is large because of the high $\mathrm{O} / \mathrm{N}_{2}$ ratio. But in "far-from-pole" longitudes, the downwelling zones are at high geographic latitudes and receive little or no direct sunlight in winter. So the electron density is very low at mid-winter, despite the high $\mathrm{O} / \mathrm{N}_{2}$ ratio, and this accounts for the tendency towards equinoctial (semiannual) maxima of $N m \mathrm{~F} 2$ in "far-from-pole" longitudes.

These features appear in CTIP noon maps, Fig. 5 of Zou et al. (2000), in which the high latitude areas of depressed $N m \mathrm{~F} 2$ are centred about $70^{\circ} \mathrm{N}, 90^{\circ} \mathrm{E}$ geographic in December and $70^{\circ} \mathrm{S}, 90^{\circ} \mathrm{W}$ in June. Although the satellite did not reach latitudes of total winter darkness, the AE-C data do show high values of $P$-parameter (large $\mathrm{O} / \mathrm{N}_{2}$ ratio) in these longitudes at latitudes above $60^{\circ}$, especially in the north (Figs. 3 and 4), as predicted by CTIP. Clearly, composition data from higher latitudes are needed to confirm our interpretation.

However, the summer/winter range of $P$ is clearly greater in the model than in the data. Winter $P$-values in CTIP are too large because the model overestimates the downwelling there, the reason being that the model lacks any mechanism, such as an additional heating source, for generating sufficient upwelling in winter. This lack is most noticeable in regions where there is no sunlight at all, but it has little effect in the summer hemisphere or at equinox. Obviously, downwelling and upwellling must balance globally; but our results suggest that the winter downwelling is actually less intensive, and must, therefore, be more widely distributed than is portrayed by CTIP.

We should note that our CTIP simulations do not consider the effects of tidal forcing from below. Tides generated in the troposphere and stratosphere propagate into the lower thermosphere, dissipating their energy at $100-150 \mathrm{~km}$ altitude, thus releasing considerable amounts of momentum and energy into the region. This may generate additional upwelling at mid-latitudes, thus potentially reducing the $\mathrm{O} / \mathrm{N}_{2}$ ratio and $P$ in the winter hemisphere - a possible reason for the discrepancy between CTIP and MSIS.

The AE-C maps (Figs. 3-5) show some alignment with magnetic $L$-shells, which also appears in the CTIP results. This is not surprising, since the model is driven by high latitude energy inputs as well as by solar heating. However, it is probably not useful to relate the CTIP maps in detail to $L$-values. Our version of CTIP relies entirely on the statistical high latitude inputs, as given empirically by Foster et al. (1986) (from averages of Millstone Hill observations of convection fields) and by Fuller-Rowell and Evans (1987) (from Tiros satellite data on particle precipitation). These are limited data sets that have undergone much processing, including averaging over many seasons and binning with $K_{p}$. Finally, the CTIP profiles are smooth because the model omits any physical processes of fine spatial scale or short time-scale. The only source of short-term variability in CTIP 
is the diurnal variation of solar heating; even the magnetic forcing is UT-independent.

\section{Conclusions}

1. The AE-C data show strong seasonal variations of neutral composition, with greatest $P$-parameter and $\mathrm{O} / \mathrm{N}_{2}$ ratio in winter near solstice, though not necessarily at solstice.

2. The solstice maps show that $P$, and, therefore, the $\mathrm{O} / \mathrm{N}_{2}$ ratio at fixed pressure-levels, increases steadily from summer to winter.

3. The AE-C data confirm fairly well the results of the CTIP modelling of Rishbeth et al. (2000), which indicate strong summer/winter variations of the $P$ parameter $\left(\mathrm{O} / \mathrm{N}_{2}\right.$ ratio) in longitude sectors near the magnetic poles, but a tendency towards equinoctial maxima of $P$ elsewhere. In the data, however, semiannual variations of $P$ appear weak, except perhaps in western mid-latitudes in the Southern Hemisphere.

4. Magnetic disturbance decreases $P$ at high latitudes. There are smaller effects at midlatitudes, namely some decrease in summer and a small increase in winter, consistent with the well-known seasonal variations of F2-layer disturbances. We have not studied individual storms.

5. We combine data from all local times, and, therefore, cannot discuss local time effects in detail; but by comparing daytime values of $P$ with values for all local times, we found that the composition does not vary greatly from day to night. This agrees with CTIP modelling by Rishbeth and Müller-Wodarg (1999), which gave day-to-night changes in $P$ of only about 5 (their Fig. 2), consistent with the time constant for composition changes, which is estimated to be of the order 20 days (Rishbeth et al., 2000). The MSIS day-to-night changes of $P$, too, are typically 5 units.

6. The CTIP model overestimates the winter increases in the $P$-parameter (or $\mathrm{O} / \mathrm{N}_{2}$ ratio) produced by downwelling at high winter mid-latitudes, more so in the south than the north. This implies that the model lacks some process, such as an additional energy source, which opposes the downwelling in the winter hemisphere.

7. Values of the $P$-parameter computed from the MSIS model, for places at northern and southern midlatitudes, broadly agree with values given by AE-C, but in general portray a more molecular thermosphere than do the AE-C data, while the CTIP thermosphere is rather more molecular than is shown by MSIS. This may imply some systematic error in the derived $\mathrm{O} / \mathrm{O}_{2}$ ratios, but we do not attempt to pursue the matter in this paper.
8. The latitude/longitude maps give no evidence of any equatorial effect in thermospheric composition, so composition plays no part in forming the F2-layer equatorial anomaly.

In summary, we have shown that the NATE data from the AE-C satellite provide a useful means of investigating thermospheric composition; these data show marked winter/summer variations of composition, which broadly confirm the "composition change" theory of F2-layer seasonal and magnetic storm variations, and the results agree quite well with both the theoretical CTIP and empirical MSIS models of the thermosphere with regards to the mean composition, though not necessarily in the details of its variations.

Acknowledgements. We wish to thank the National Space Science Data Centre A for providing the AE-C unified abstract data. The work at UT Dallas is supported by NASA grant NAG 5-10271. IM-W was funded by the British Particle Physics and Astronomy Research Council (PPARC) grant PPA/G/O/1999/00667 and since 2002 by the British Royal Society. All CTIP model calculations were carried out on the High Performance Service for Physics, Astronomy, Chemistry and Earth Sciences (HiPer-SPACE) Silicon Graphics Origin 2000 Supercomputer located at University College London and funded by PPARC.

Topical Editor M. Lester thanks C. Fesen and R. Balthazor for their help in evaluating this paper.

\section{Appendix A The compositional $P$-parameter}

To overcome the difficulty that the $\mathrm{O} / \mathrm{N}_{2}$ ratio varies rapidly with height, we express our results in terms of the " $P$-parameter", much as defined by Rishbeth and MüllerWodarg (1999). Let $\zeta$ denote "reduced height", measured from a base height ho in units of the pressure scale height of atomic hydrogen. This scale height is given by $H_{1}=R T / g$, and is about $1000 \mathrm{~km}$, where $R$ is the universal gas constant, $T$ is temperature, and $g$ is the gravitational acceleration (as $H_{1}$ varies with height, the relation between $Z$ and the real height $h$ involves an integration, but this is a detail we need not consider here).

The base height ho is at around $120 \mathrm{~km}$, above which height the gases $\mathrm{O}$ and $\mathrm{N}_{2}$ may be assumed to be distributed with their own scale heights in the ratio 28/16. Let the suffix " $o$ " denote values of parameters at the base level ho. In terms of natural logarithms, the gas concentrations vary with height above ho according to the equations:

$\ln [\mathrm{O}]=\ln (T o / T)+\ln [\mathrm{O}] o-16 \zeta$

$\ln \left[\mathrm{N}_{2}\right]=\ln (T o / T)+\ln \left[\mathrm{N}_{2}\right] o-28 \zeta$.

Multiplying Eq. (A1) by 28 and Eq. (A2) by 16, and subtracting to cancel the terms in $\zeta$, we have

$28 \ln [\mathrm{O}]-16 \ln \left[\mathrm{N}_{2}\right]+12 \ln T=P$

$=28 \ln [\mathrm{O}] o-16 \ln \left[\mathrm{N}_{2}\right] o+12 \ln T o$. 
The left-hand side of Eq. (A3) is the $P$-parameter, as defined by Rishbeth and Müller-Wodarg (1999). The numerical values of $P$ depend on the $\mathrm{O} / \mathrm{N}_{2}$ ratio and also on the units of concentration (here $\mathrm{m}^{-3}$ ). The relation between $P$ and $\mathrm{ln}$ $\left[\mathrm{O} / \mathrm{N}_{2}\right]$ is not quite linear, and depends weakly on the $\mathrm{O} / \mathrm{N}_{2}$ ratio. For the $\mathrm{O} / \mathrm{N}_{2}$ ratios prevalent at the F2-peak, a 5\% increase in the $\mathrm{O} / \mathrm{N}_{2}$ ratio corresponds to a change in $P$ by about +1 unit. Larger changes in $P$, for example, by 10 and 25 units, change the $\mathrm{O} / \mathrm{N}_{2}$ ratio by factors of about 1.8 and 4 , respectively.

The temperature term $12 \ln T$ is not particularly important and, as explained in Sect. 2.3, we omit it for the purposes of this paper. Instead, we take

$$
P=28 \ln [\mathrm{O}]-16 \ln \left[\mathrm{N}_{2}\right] .
$$

This modified $P$ is not exactly height-independent, because the temperature term $12 \ln T$ in Eq. (A3) changes by 1.2 if the temperature changes by $10 \%$. However, this has little effect on our results. According to the empirical MSIS model (Hedin, 1987), for the range of solar activity spanned by our AE-C data and for moderate geomagnetic activity $\left(K_{p}<3\right)$, the temperature at F2-layer heights (not much different from the "exospheric temperature") varies at midlatitudes by about $30 \%$ between day and night and $20 \%$ between summer and winter. These temperature changes cause our "simplified $P$ " to vary by about \pm 1.8 diurnally and \pm 1.2 seasonally. In comparison, the seasonal and latitudinal changes of $P$ span some tens of units, so the temperature term does not appreciably contribute to these variations.

\section{References}

Berkner, L. V., Wells, H. W., and Seaton, S. L.: Characteristics of the upper region of the ionosphere, Terr. Magn. Atmos. Elect., 41, 173-184, 1936.

Dalgarno, A., Hanson, W. B., Spencer, N. W., and Schmerling, E. R.: The Atmospheric Explorer Mission, Radio Sci., 8, 263-266, 1973.

Duncan, R. A.: F-region seasonal and magnetic storm behaviour. J. Atmos. Terr. Phys., 31, 59-70, 1969.

Foster, J. C., Holt, J. M., Musgrove, R. G., and Evans, D. S.: Ionospheric convection associated with discrete levels of particle precipitation, Geophys. Res. Lett., 13, 656-659, 1986.

Fuller-Rowell, T. J.: The "thermospheric spoon": A mechanism for the semi-annual density variation, J. Geophys. Res., 103, 39513956, 1998.
Fuller-Rowell, T. J. and Evans, D. S.: Height-integrated Pedersen and Hall conductivity patterns inferred from the TIROS-NOAA satellite data, J. Geophys. Res., 92, 7606-7618, 1987.

Fuller-Rowell, T. J., Rees, D., Quegan, S., Moffett, R. J., Codrescu, M. V., and Millward, G. H.: A coupled thermosphere-ionosphere model (CTIM), in: STEP Handbook of Ionospheric Models, edited by Schunk, R. W., Utah State University, Logan, Utah, 217-238, 1996.

Hedin, A. E.: MSIS-86 thermospheric model, J. Geophys. Res., 92, 4649-4662, 1987.

Mauersberger, K., Kayser, D. C., Potter, W. E., and Nier, A. O.: Seasonal variation of neutral thermospheric constituents in the northern hemisphere, J. Geophys. Res., 81, 7-11, 1976.

Millward, G. H., Rishbeth, H., Moffett, R. J., Quegan, S., and Fuller-Rowell, T. J.: Ionospheric F2-layer seasonal and semiannual variations. J. Geophys. Res. 101, 5149-5156, 1996 .

Millward, G. H., Moffett, R. J., Quegan, S., and Fuller-Rowell, T. J.: A coupled thermosphere-ionosphere-plasmasphere model (CTIP), in: STEP Handbook of Ionospheric Models, edited by Schunk, R. W., Utah State University, Logan, Utah, 239-280, 1996b.

Rishbeth, H.: Questions of the equatorial F2-layer and thermosphere, J. Atmos. Solar-Terr. Phys., accepted, 2003.

Rishbeth, H. and Setty, C. S. G. K.: The F-layer at sunrise, J. Atmos. Terr. Phys., 21, 263-276, 1961.

Rishbeth, H. and Müller-Wodarg, I. C. F.: Vertical circulation and thermospheric composition: a modelling study, Ann. Geophysicae, 17, 794-805, 1999.

Rishbeth, H., Müller-Wodarg, I. C. F., Zou, L., Fuller-Rowell, T. J., Millward, G. H., Moffett, R. J., Idenden, D. W., and Aylward, A. D.: Annual and semiannual variations in the ionospheric F2layer: II. Physical discussion, Ann. Geophysicae, 18, 945-956, 2000.

Spencer, N. W., Niemann, H. B., and Carignan, G. R.: The neutralatmosphere temperature experiment, Radio Sci., 8, 287-296, 1973.

Torr, M. R. and Torr, D. G.: The seasonal behaviour of the F2-layer of the ionosphere, J. Atmos. Terr. Phys., 35, 2237-2251, 1973.

von Zahn, U., Fricke, K. H., and Trinks, H.: Esro 4 gas analyzer results, I. First observations of the summer argon bulge, J. Geophys. Res., 78, 7560-7562, 1973.

Yonezawa, T.: The solar-activity and latitudinal characteristics of the seasonal, non-seasonal and semi-annual variations in the peak electron densities of the F2-layer at noon and at midnight in middle and low latitudes, J. Atmos. Terr. Phys., 33, 889-907, 1971.

Zou, L., Rishbeth, H., Müller-Wodarg, I. C. F., Aylward, A. D., Millward, G. H., Fuller-Rowell, T. J., Idenden, D. W., and Moffett, R. J.: Annual and semiannual variations in the ionospheric F2-layer: I. Modelling, Ann. Geophysicae, 18, 927-944, 2000. 